ISSN: 0213-2060

DOI: https://doi.org/10.14201/shhme2019371165185

\title{
LLIBRE DE CONFRARIA DEL ROSER DEL ANY 1489 DEL MONASTERIO DE SANTA MARÍA DE MONTESIÓN DE BARCELONA: UN EJEMPLO DE RED DEVOCIONAL
}

\author{
Book of the Confraternity of the Rosary (1489) of the Convent of Holy Mary \\ of Mount Zion of Barcelona: A Source for a Devotional Network
}

Concepción RODRÍGUEZ-PARADA

Departament de Biblioteconomia, Documentació i Comunicació Audiovisual. Facultat de Biblioteconomia i Documentació. Universitat de Barcelona. C/ Melcior de Palau, 140. E-08014 BARCELONA. C. e.: crodriguezp@ub.edu

\section{Núria JORNET BENITO}

Departament de Biblioteconomia, Documentació i Comunicació Audiovisual. Facultat de Biblioteconomia i Documentació. Universitat de Barcelona. C/ Melcior de Palau, 140.E-08014BARCELONA. C. e.: jornet@ub.edu

Recibido: 2018-03-01

Revisado: 2019-04-14

Aceptado: 2019-04-30

RESUMEN: Este trabajo forma parte del proyecto de investigación Paisajes espirituales. Modelos de aproximación espacial a las transformaciones de la religiosidad femenina medieval en los reinos peninsulares (siglos XII-XVI) (http://www.ub.edu/proyectopaisajes/index.php). Desde este marco teórico, nuestros objetivos se centran en mostrar y analizar un libro de cofradías para descubrir el potencial de esta fuente como punto de partida para llevar a cabo una investigación centrada en la fundación y el desarrollo de hermandades devocionales en la Edad Media; y, en segundo lugar, ilustrar la relevancia del método prosopográfico para visualizar el papel activo de los laicos en la sociedad tardo-medieval, y las redes espirituales y de solidaridad que se establecen entre los hermanos, que provienen de diferentes áreas geográficas y sociales. Finalmente, la fecha temprana de la fundación de la cofradía del Rosario en el monasterio de Santa María de Montesión (Barcelona) en 1488, por iniciativa de Juana de Aragón, revela el importante papel que esta comunidad de dominicas jugó en la sociedad de Barcelona de su tiempo y su ubicación en la topografía espiritual del momento.

Palabras clave: Monasterio de Santa María de Montesión de Barcelona; Cofradía del Rosario; Juana de Aragón; Libro de cofradía. 
LLIBRE DE CONFRARIA DEL ROSER DEL ANY 1489 DEL MONASTERIO DE SANTA MARÍA DE MONTESIÓN DE BARCELONA: UN EJEMPLO DE RED DEVOCIONAL CONCEPCIÓN RODRÍGUEZ-PARADA Y NÚRIA JORNET BENITO

ABSTRACT: This paper forms part from the research project Spiritual Landscapes Model of Spatial Analysis of the Transformation of Women's Medieval Religiosity in the Iberian Kingdoms (12 $2^{\text {th }}-16^{\text {th }}$ Centuries) (http://www.ub.edu/proyectopaisajes/index.php). Our aim is to show and analyse a confraternity book, and to discover the potential of this source as a starting point to carry out an investigation focused on the foundation and development of devotional brotherhoods in the Middle Ages. Finally, to illustrate the relevance of the prosopographical method to visualize the active role of laypersons in late medieval society, and the spiritual and solidarity networks that are established between the brothers, who come from different geographical and social areas. The early date of the foundation of a brotherhood in the convent of the Dominican nuns of Santa Maria de Montesión (Barcelona) in 1488 on doña Juana de Aragón initiative reveals the important role played by these Dominican nuns in the society of Barcelona in this period and its position of spiritual topography.

Keywords: Convent of Holy Mary of Mount Zion of Barcelona; Confraternity of the Rosary; Juana de Aragón; Confraternity Book.

SUMARIO: 0 Introducción. 1 El monasterio de dominicas de Santa María de Montesión de Barcelona (s. xIV-Xv). 2 La fundación de cofradías. 3 La cofradía del Rosario del monasterio de Montesión. 4 El Llibre de Confraria del Roser del any 1489. 5 Conclusiones. 6 Referencias bibliográficas.

\section{INTRODUCCIÓN}

Este artículo se sitúa en el marco del proyecto de investigación multidisciplinar Spiritual Landscapes, Models of Spatial Approach to Medieval Female Religious Transformations in the Peninsular Kingdoms (12 $12^{\text {th }}-16^{\text {th }}$ Centuries) (http://www.ub.edu/proyectopaisajes/index.php/the-project/about-sl), que lidera la Universidad de Barcelona junto a otras universidades españolas e internacionales, y que tiene como objetivo principal avanzar en una propuesta metodológica que explore las posibilidades de un análisis holístico del paisaje y las aproximaciones, a diferentes escalas espaciales, al fenómeno religioso en la Europa medieval y de manera especial el protagonizado por las mujeres. Se trata de una investigación centrada en cuatro ejes que abordan los espacios de la espiritualidad medieval desde diferentes perspectivas: la inclusión de los espacios en un contexto amplio para elaborar cartografías diacrónicas que evidencien dinámicas fundacionales y evolutivas (Paisajes monásticos); la integración del monasterio u otro tipo de espacio de religiosidad en su entorno circundante para visualizar su patrimonio y red de impacto e influencias (El monasterio y su entorno); el análisis del contexto funcional y performativo del espacio con sus objetos y prácticas para recrear una topografía interior del monasterio bajomedieval (El monasterio interior); el análisis del contexto relacional para visualizar relaciones, circulación de ideas y personas en el espacio (Redes en contextos de reforma y/o disidencia) ${ }^{1}$.

1 Proyecto del IRCVM (Institut de Recerca en Cultures Medievals) de la Universitat de Barcelona financiado por el Ministerio de Economía y Competitividad 2015-2017 (HAR2014-52198-P). Primeros 
LLIBRE DE CONFRARIA DEL ROSER DEL ANY 1489 DEL MONASTERIO DE SANTA MARÍA DE MONTESIÓN DE BARCELONA: UN EJEMPLO DE RED DEVOCIONAL CONCEPCIÓN RODRÍGUEZ-PARADA Y NÚRIA JORNET BENITO

Nuestro trabajo se centra en la cofradía de la Verge Maria de la Rosa de Montissión, fundada oficialmente en 1488 bajo el patrocinio de doña Juana de Aragón, hija del rey Fernando II de Aragón y de la plebeya Joana Nicolau, en el monasterio de dominicas de Barcelona, y de manera particular a partir de su segundo «libro de cofradía» que se conserva en el Archivo Histórico de la Provincia de Aragón de la Orden de Predicadores (AHPA) con sede en Valencia. El objetivo que perseguimos es doble: por un lado, mostrar la estructura relacional de nombres y geografías tejida en torno a la devoción al Rosario tal como se refleja en dicho libro; del otro, dar a conocer una tipología documental propia de estas asociaciones y mostrar las diversas posibilidades de estudio que ofrece (histórico, diplomático, archivístico, etc.).

Esta investigación nos permitirá, asimismo, situar el monasterio de dominicas de Barcelona en la topografía monástica bajomedieval y visibilizar el rol de esta comunidad de predicadoras en las prácticas devocionales del momento y en la consolidación del culto al Rosario. Y, asimismo, otorgar un papel relevante a la monarquía y en particular a las hijas y miembros femeninos de la corte, tanto en la fundación de espacios -dando origen al monasterio-, como en el mecenazgo y la promoción de prácticas espirituales - mediante la fundación de cofradías, por ejemplo- ${ }^{2}$.

El artículo se estructura en 5 partes. En las dos primeras, hacemos un breve repaso histórico del monasterio de Montesión y de la fundación de las cofradías en la Edad Media; en la tercera, a partir de las fuentes documentales, nos centramos en la cofradía de la Verge Maria de la Rosa de Montission; en la cuarta, analizamos el contenido de su llibre segon ${ }^{3}$; y, finalmente, presentamos las conclusiones. El trabajo es, en cualquier caso, una primera aproximación, de carácter tipológico, a este libro, contextualizándolo en la historia del monasterio barcelonés, en la historia de la religiosidad medieval en general y de las cofradías en particular, haciendo especial incidencia en las escasas fuentes documentales localizadas hasta ahora y en los pocos estudios que, hasta el momento, recogen y sintetizan lo que se conoce acerca de esta cofradía.

Ciertamente, el estudio de las cofradías devocionales constituye un aspecto clave en un proyecto que busca reconstruir el paisaje espiritual medieval. En primer lugar, en tanto que las cofradías se erigen como espacio devocional enraizado, en el caso que nos ocupa, en una iglesia monástica, que se abre a su entorno geográfico y social más o menos cercano. Por otro, las cofradías pueden analizarse también desde la perspectiva de nuestro cuarto modelo de aproximación espacial, esto es, como generadoras de una red de relaciones. Finalmente, y como ha señalado Marina Gazzinit en una reciente obra que

resultados presentados de manera colectiva en: Colesanti, Gemma-Teresa; Garí, Blanca y JoRnet Benito, Núria (coords.). Clarisas y dominicas. Modelos de implantación, filiación, promoción y devoción en la Peninsula Ibérica, Cerdeña, Nápoles y Sicilia. Firenze: Reti Medievali Firenze University Press, 2017.

2 Hemos tratado más específicamente la fundación de la cofradía del Rosario en Barcelona en: RoDríguez-Parada, Concepción. «Los orígenes de la Cofradía del Rosario del monasterio de Santa María de Montesión». En Colesanti, Garí y Jornet Benito (coords.), Clarisas y dominicas, pp. 409-428.

3 Llibre de Confraria del Roser del any 1489. Archivo Histórico de la Provincia de Aragón de la Orden de Predicadores (AHPA).

4 GazzinI, Marina (a cura di). Studi confraternali. Orientamenti, problemi, testimonianze. Firenze: Reti Medievali, 2009, p. IX (Presentazione). 
LLIBRE DE CONFRARIA DEL ROSER DEL ANY 1489 DEL MONASTERIO DE SANTA MARÍA DE MONTESIÓN DE BARCELONA: UN EJEMPLO DE RED DEVOCIONAL

aborda los principales aspectos y problemáticas de las cofradías en la Edad Media, se trata de un ámbito de estudio que se ha consolidado en las últimas décadas al converger distintos intereses interrelacionados: las formas de asociacionismo con trasfondo religioso, las funciones caritativas y asistenciales de la sociedad medieval, y, especialmente en nuestro caso, la revalorización del rol del laicado en la Iglesia en el sentido que las cofradías son expresión de una religiosidad laical que toma un especial protagonismo en este tiempo.

Sin pretender hacer una exhaustiva revisión bibliográfica, que se escapa por otro lado de nuestros objetivos, ya Esther Tello Hernández', en el caso español, sitúa en la XIX Semana de Estudios Medievales (1991) la eclosión y apertura de nuevos horizontes en el estudio de las cofradías en Espańa porque pasan a abordarse desde una perspectiva interdisciplinar (Sociología, Antropología, Historia del Arte, Historia de la Iglesia, Derecho, Economía, etc.). No obstante, han sido Inmaculada Arias de Saavedra y Miguel Luis López-Guadalupe Muñoz los que han dedicado mayores esfuerzos a historiografiarlas. Recientemente han publicado una exhaustiva bibliografía ${ }^{6}$ sobre la vertiente social de las cofradías en los últimos 30 años que, aunque centrada en la época moderna, no olvida mencionar los autores que han estudiado estas asociaciones en la Edad Media, como Martín-Viveros Tajuelo7, Egido López ${ }^{8}$ y Godaracena Arboleda ${ }^{9}$, entre otros, a los que nosotros añadimos Benítez Bolorinos ${ }^{10}$, Iradiel Murugarren ${ }^{11}$, Navarro Espinach ${ }^{12} \mathrm{y}$ Pérez González ${ }^{13}$, por ejemplo.

Si nos circunscribimos a las cofradías dedicadas a la Virgen del Rosario, su máximo estudioso en Espańa, Carlos Romero Mensaque, afirmaba en 2014 la existencia de numerosos trabajos de ámbito local sobre arte, iconografía, folklore y etnografía, a la vez

5 Tello Hernández, Esther. Aportación al estudio de las cofradías medievales y sus devociones en el reino de Aragón. Zaragoza: Fundación Fernando el Católico, 2013, pp. 19-20<https://ifc.dpz.es/recursos/ publicaciones/33/20/_ebook.pdf> [Consulta: 20/12/2017].

6 Arias de SaAvedra, Inmaculada y López-Guadalupe Muñoz, Miguel Luis. «Las cofradías españolas de la Edad Moderna desde una óptica social. Tres décadas de avance historiográfico». Cuadernos de Estudios del Siglo XVIII, 2017, vol. 27, pp. 11-50 <https://doi.org/10.17811/cesxviii.27.2017.11-50> [Consulta: 20/12/2017].

7 Martín-Viveros Tajuelo, Antonio. «Las cofradías castellanas en la Edad Media: pasado, presente y futuro de la producción historiográfica». Espacio, Tiempo y Forma. Serie III. Historia Medieval, 2012, vol. 25, pp. 285-308.

8 Egido López, Teófanes. «La religiosidad colectiva de los vallisoletanos». En Valladolid en el siglo XVIII. Valladolid: Ateneo, 1984, pp. 157-260.

9 Godaracena Arboleda, Juan Carlos. «Creencias y devociones en las cofradías sevillanas de finales de la Edad Media y comienzos de la modernidad». Revista de Humanidades, 2016, vol. 29, pp. 9-36 <http:// revistas.uned.es/index.php/rdh/article/view/17215/14701> [Consulta: 07/04/2019].

10 Benítez Bolorinos, Manuel. «Las cofradías en el Reino de Valencia: análisis y claves interpretativas». Anuario de Estudios Medievales, 2006, vol. 36, n. ${ }^{\circ}$ 2, pp. 553-581.

11 Iradiel Murugarren, Paulino. "Corporaciones de oficio, acción política y sociedad civil en Valencia». En Cofradias, gremios y solidaridades en la Europa medieval. XIX Semana de Estudios Medievales. Estella, 20 a 24 de julio de 1992. Pamplona: Gobierno de Navarra, 1993, pp. 253-284.

12 Navarro Espinach, Germán. «Las cofradías medievales en España». Historia 396, vol. 4, n. ${ }^{\circ} 1$, 2014, pp. 107-133 <https://dialnet.unirioja.es/servlet/articulo?codigo=5627994> [Consulta: 07/04/2019].

13 Pérez González, Silvia María. «Nuevas aportaciones al estudio de las cofradías y hermandades en la Castilla bajomedieval: el ejemplo de Jerez de la Frontera». Hispania Sacra, 2016, vol. 68, n. ${ }^{\circ}$ 138, pp. 503-520 <https://doi.org/10.3989/hs.2016.032> [Consulta: 07/04/2019]. 
LLIBRE DE CONFRARIA DEL ROSER DEL ANY 1489 DEL MONASTERIO DE SANTA MARÍA DE MONTESIÓN DE BARCELONA: UN EJEMPLO DE RED DEVOCIONAL CONCEPCIÓN RODRÍGUEZ-PARADA Y NÚRIA JORNET BENITO

que destacaba la ausencia de aproximaciones globales que explicaran la importancia y la amplísima implantación territorial de dicha devoción en el estado español ${ }^{14}$. Su diagnóstico poco ha cambiado a día de hoy ${ }^{15}$. No obstante, cabe subrayar que en Cataluña se han dado algunos avances importantes en el conocimiento de las cofradías del Rosario en la Edad Moderna. Destacamos, sobre todo, la tesis doctoral de Caterina Capdevila, centrada en la diócesis de Girona (siglos XVI-XIX) ${ }^{16}$, y, aunque de manera más indirecta, los estudios de Joaquim M. Puigvert sobre las redes de sociabilidad generadas en el territorio rural por parroquias y cofradías ${ }^{17}$.

1 El monasterio de dominicas de Santa María de Montesión de Barcelona (s. $\mathrm{XIV}-\mathrm{XV}$ )

Casi todo lo que sabemos de las predicadoras barcelonesas se lo debemos al historiador Antonio Paulí Menéndez que, tras consultar protocolos notariales y los fondos del archivo monástico, ha escrito la que hasta la fecha es la monografía de referencia sobre el devenir de las religiosas de Montesión ${ }^{18}$. La obra de Paulí nos permite conocer también la trayectoria del resto de conventos femeninos barceloneses, lo que lleva a Mercè Tatjer a equipararlo con el historiador de las órdenes masculinas catalanas, Cayetano Barraquer Roviralta $^{19}$. Poco más es lo que se ha publicado sobre Santa María de Montesión, si exceptuamos el artículo de Marisol Hernández Cabrera ${ }^{20}$ y el estudio centrado en la figura de sor Àngela Pujades en su etapa al frente de la hermandad del Rosario (1521-1547) escrito por Susana Adriazola ${ }^{21}$. En el archivo conventual se conservan diversas crónicas redactadas por las mismas religiosas que, junto a los autores citados, constituyen la base de nuestro breve repaso histórico.

Las obras de construcción del monasterio se inician en 1347, año en que fallece su promotora, la infanta María (1297-1347), hija de Jaime II de Aragón, el Justo, y de

14 Romero Mensaque, Carlos. «Los comienzos del fenómeno rosariano en la España moderna. La etapa fundacional, siglos xv y xvI». Hispania Sacra, 2014, vol. 66, n.o 2, pp. 243-278<http://hispaniasacra. revistas.csic.es/index.php/hispaniasacra/article/viewArticle/419> [Consulta: 22/05/2017].

15 Rodríguez-PARADA, «Los orígenes de la Cofradía del Rosario».

16 CAPDEVILA, Caterina. La devoció del Roser a la diòcesi de Girona del segle XVI al XIX: confraries i imatges. Tesis doctoral dirigida por el Dr. Bonaventura Bassegoda. Universitat Autònoma de Barcelona, 2015 <http://hdl.handle.net/10803/322794> [Consulta: 10/04/2019].

17 Puigvert i Solà, Joaquim M. Església, territori i sociabilitat, ss. XVII-XIX. Vic: Eumo, 2001.

18 Paulí Menéndez, Antonio. El Real Monasterio de Santa María de Monte-Sión de Barcelona. Barcelona: Bartrés, 1952.

19 TATJER, Mercè. Burgueses, inquilinos y rentistas: mercado inmobiliario, propiedad y morfología en el centro histórico de Barcelona: La Barceloneta 1753-1982. Madrid: Consejo Superior de Investigaciones Científicas, 1998, p. 121.

20 Hernández Cabrera, Marisol. «La celda del convento una habitación propia. La vivencia de la clausura en la comunidad de dominicas de Montesión». Duoda. Revista d'Estudis Feministes, 2002, vol. 22, pp. 19-40 <http://www.raco.cat/index.php/duoda/article/viewFile/62697/90792> [Consulta: 22/12/2017].

21 Adriazola Acha, Susana. «Fragmentos de una vida: Ángela Pujades, escritura y devoción al Rosario». En Garí, Blanca (ed.). Vida de mujeres del Renacimiento. Barcelona: Publicacions i Edicions de la Universitat de Barcelona, 2007, pp. 163-185. 
LLIBRE DE CONFRARIA DEL ROSER DEL ANY 1489 DEL MONASTERIO DE SANTA MARÍA DE MONTESIÓN DE BARCELONA: UN EJEMPLO DE RED DEVOCIONAL

Blanca de Nápoles. Tras enviudar del infante Pedro, hijo del rey Sancho IV de Castilla, profesa en el convento de Sijena de religiosas hospitalarias de la Orden de San Juan de Jerusalén del que su hermana Blanca era priora. Una vez obtenido el permiso de esta, María concita los apoyos del papa Clemente VI, de su confesor, fr. Nicolás Rosell O. P., de fr. Bernardo Sescala, prior provincial de los dominicos y de su sobrino, el rey Pedro III el Ceremonioso, para fundar un convento de religiosas predicadoras en Barcelona.

Mientras se edificaba el monasterio, las primeras religiosas, que procedían de Prouilhe (Languedoc), ocuparon una casa en el portal de Jonqueres (1351) y después la antigua encomienda templaria de Santa María de Palau. Finalmente, en 1357, concluidas las obras, se trasladan al nuevo convento puesto bajo la advocación del dominico San Pedro Mártir que estaba en el Mas d'en Bissanya, un emplazamiento situado fuera de la muralla próximo a las Atarazanas. El lugar estaba desprotegido de las frecuentes incursiones piratas, por lo que las monjas en 1370 emprenden un nuevo éxodo hasta la Casa d'en Porta, cerca del Hospital d'en Colom en el Raval de Barcelona, que les fue cedida por el rey Pedro. No será este el último cambio, puesto que en 1423 se instalan en un convento ubicado en la plaza de Santa Ana ocupado hasta entonces por los canónigos agustinos de Santa Eulalia del Campo. A partir de este momento abandonan el patrocinio del protomártir dominico y toman el de Santa María -como era deseo de la infanta fundadorabajo la invocación de su Presentación en el templo o Monte-Sión.

El monasterio de dominicas de Barcelona encara, pues, su trayectoria de vida en el siglo XV -centuria en la que se creará en su seno la cofradía del Rosario- instalado en plena trama urbana de la Barcelona medieval. Durante esta centuria, y hasta la implantación de la reforma tridentina, la comunidad vivió una época de prosperidad económica que se reflejó en el patrimonio monástico. Asimismo, debió tener una importante significación espiritual e intelectual, como lo demuestra, por ejemplo, la creación de tres cofradías entre 1488 y 1534: la del Rosario, primera en el tiempo y objeto de nuestro estudio, la de Santa Apolonia y la de San Nicasio ${ }^{22}$.

\section{LA FUNDACIÓN DE COFRADÍAS}

El horizonte espiritual del siglo XIII se caracteriza por la fundación de órdenes mendicantes y, como hemos comentado, por el creciente protagonismo de los laicos que buscan nuevos modos y nuevos espacios en los que expresar su vivencia religiosa al margen de la Iglesia oficial o, cuando menos, sustrayéndose en parte a su control y tutela directa. En el contexto descrito de progresiva laicización de la sociedad, la existencia de cofradías cobra especial importancia, porque, a pesar de la existencia de algunas solo para clérigos, hay estudiosos que sostienen que "fueron las instituciones eclesiásticas más auténticamente laicales y de laicos [...] han nacido entre ellos y se mantuvieron entre los laicos ${ }^{23}$.

22 Garí, Blanca. «Santa Maria de Montsió». Claustra. Catálogo de los Reinos peninsulares <http://www. ub.edu/claustra/Monestirs/view/20> [Consulta: 26/01/2018].

23 Pérez González, Silvia María. «Mujeres y cofradías en la Andalucía de la Baja Edad Media». Historia. Instituciones. Documentos, 2012, vol. 39, p. 3. También accesible en: <http://hdl.handle.net/10433/1161> [Consulta: 10/01/2018]. 
LLIBRE DE CONFRARIA DEL ROSER DEL ANY 1489 DEL MONASTERIO DE SANTA MARÍA DE MONTESIÓN DE BARCELONA: UN EJEMPLO DE RED DEVOCIONAL CONCEPCIÓN RODRÍGUEZ-PARADA Y NÚRIA JORNET BENITO

Las cofradías religiosas que se fundan en los siglos XIII y XIV, nacen al calor de las nuevas inquietudes espirituales manifestadas por los habitantes de las ciudades recién creadas a la vez que ponen de manifiesto la necesidad que los fieles tenían de conseguir la solidaridad espiritual y material de sus hermanos cofrades. Las ordenanzas por las que se regían contemplaban tres aspectos esenciales: organizativos (admisión de cofrades, pago de cuotas, elección de mayorales...); religiosos (culto a la advocación, celebración de sufragios por los hermanos difuntos...); y asistenciales (auxilio de cofrades necesitados, organización y pago de exequias, etc.). A través de la práctica caritativa y de la plegaria, estas cofradías ofrecían amparo y cobijo a la vez que saciaban en parte los anhelos de emancipación de sus miembros.

Dichas hermandades, creadas en un primer momento fuera del ámbito institucional, agrupaban a un buen número de ciudadanos. La Iglesia oficial, merced a la acción de las órdenes mendicantes, busca canalizar estas manifestaciones de espiritualidad que perseguían conseguir la solidaridad espiritual y material de los hermanos cofrades. Para ello se sirvió de la figura de la Virgen a la que el Concilio de Éfeso reconoció como mediadora entre Dios y el género humano. Su condición de "madre misericordiosa» ${ }^{24}$ se completa en el siglo Xv al añadírsele la meditación sobre la Anunciación.

En este ambiente que exalta el misterio de la Encarnación, el dominico fr. Alanus à Rupe funda en 1464 en Douai la cofradía del Psalterio de la Virgen y de Santo Domingo, precedente inmediato de las cofradías del Rosario. Un año después, siguiendo el ejemplo de Alanus, fr. Jakob Sprenger funda en Colonia la hermandad del Rosario que se expande por Europa con gran rapidez: Rostock, Lille y Ghent (1475), Augsburgo (1476), Lisboa (1478), Ulm (1483), Frankfurt (1486) y Barcelona (1488) entre otras ciudades ${ }^{25}$.

A pesar de ser una de las cofradías europeas más antiguas, la de Montesión sigue siendo una gran desconocida. Solo tenemos constancia de las investigaciones de los citados Paulí y Adriazola, además de la mención de Winston-Allen ${ }^{26}$ y del citado Romero Mensaque en lo que respecta a la fecha fundacional. Sin embargo, uno de los primeros en hablar de la existencia del segundo libro de cofradía fue el folklorista Valeri Serra i Boldú $^{27}$, que en su Llibre d'or del Rosari a Catalunya ya destacaba el gran número de cofrades inscritos, los cuales procedían de muy diversos lugares. Serra i Boldú, como años más tarde hará José M. ${ }^{a}$ Coll28 ${ }^{28}$ vinculaba - equivocadamente- el libro citado a la cofradía del Rosario del convento de predicadores de Santa Caterina de Barcelona.

24 Como muestra de ello, recordemos que Pedro Nolasco funda en Barcelona la Orden de Nuestra Señora de la Merced (o Misericordia) en 1218.

25 Winston-Allen, Anne. Stories of the rose: the making of the rosary in the Middle Age. University Park: The Pennsylvania University Press, 1997, pp. 116-117.

26 Winston-Allen, Ibidem.

27 Serra i Boldú, Valeri. Llibre d'or del Rosari a Catalunya. Barcelona: Imp. Oliva de Vilanova, 1925.

28 Coll, José M.a. "Apóstoles de la devoción rosariana antes de Lepanto en Cataluña». Analecta Sacra Tarraconensia, 1955, 28, pp. 245-254. 
LLIBRE DE CONFRARIA DEL ROSER DEL ANY 1489 DEL MONASTERIO DE SANTA MARÍA DE MONTESIÓN DE BARCELONA: UN EJEMPLO DE RED DEVOCIONAL

Tal y como comenta Marina Gazzini² ${ }^{29}$, la misma ambigüedad jurídica del concepto de "confraternità» y los continuos reajustes institucionales, jurídicos y administrativos asociados a ella influyen en la dinámica e historia de las propias cofradías y en la historia archivística de sus fondos, esto es, en la organización y conservación de la documentación que generan. Un factor este último que, sin duda, condiciona la investigación de este tipo de hermandades y la del Rosario del convento de dominicas de Santa María de Montesión de Barcelona no es una excepción ${ }^{30}$.

La fecha oficial de fundación es la del 9 de septiembre de 1488, según consta en el breve apostólico del papa Inocencio VIII recogido por el notario de Barcelona Jeroni Talavera ${ }^{31}$, merced al patronazgo de doña Juana de Aragón ${ }^{32}$ y de su padre el rey Fernando II. El documento original no se conserva en el archivo conventual pero el Capbreu alude al hecho:

«Ha molt temps que es instituida una confraria son invocació de la Santíssima e intemerada V. Maria del Roser, ab breu apostòlich allí particularment a suplicació de la Illustre Sra. $\mathrm{D}^{a}$ Joana d'Aragó atorgat per Ntre. St. Pare Innocent VIII. Donat en Roma apud S. Petrus sub annulo Piscatoris, a 9 dies del mes de setembre del any $1488{ }^{33}$.

\section{Y también el Llibre d'Antiguedats:}

«Ítem un breu apostòlich, en pergamí, otorgat per lo santíssim nostre altíssim sanct Pare, Papa_Inocensi octau, a petició i instancia de la noble dona dona Joana de Aragó, filla de la magestat del rey don Fernando, a 9 de setembre de 1488, en lo any quart de son pontificat y subsignat per Jo. [Crothoviey], sub anulo Piscatoris» ${ }^{34}$.

El patronazgo incluye, asimismo, el sostenimiento económico:

«Lo sr. Rey Dn. Carlos, emperador y Rey de Espanya, per cumplir la voluntat del sereníssim y cathòlic Rey Don Fernando, son pare, la promesa que havia fet la Illma. Sra. Da Joana de Aragó, sa filla, la qual havia promés per la sustentació o manutenció de la capella

29 GazzINI, Marina. «Gli archivi delle confraternite: documentazione, prassi conservative, memoria comunitaria». En Studi confraternali, p. 372 <http://www.rmoa.unina.it/2331/1/15.Gazzini.pdf> [Consulta: 07/04/2019].

30 La conservación y los lugares de custodia de la documentación de la cofradía del Rosario de Montesión refleja muy bien lo expuesto por Gazzini. En primer lugar, su dispersión: el archivo del monasterio conserva algunas de las actas de los capítulos y reuniones de la cofradía, en concreto de la época de la priora Ángela Pujades que, como sabemos bien por el estudio de Adriazola, impulsó una reorganización importante de la cofradía que implicó la redacción de unas nuevas ordenanzas (1531). En el Archivo Provincial de Aragón de la Orden de Predicadores, en Valencia, se conservan 3 libros de contabilidad correspondientes al siglo XIX.

31 Arxiu Històric de Protocols de Barcelona (AHPB). Jeroni Talavera, AHPB 442/51, Manual 53 (1566-1609), legajo 7. Memorial de les scriptures fahents per la confraria de Nostra Señora del Roser, fundada en lsglesia y monestir de les monges de Montesión en la present ciutat de Barcelona. Citado por AdriazOla AcHA, Susana. Fragmentos de una vida: Àngela Pujades (ca. 1491-1548). Escritura y devoción al rosario. Trabajo para optar al Diploma de Estudios Avanzados [inédito]. p. 97; y Paulí Menéndez, El Real Monasterio, p. 54.

32 Se trata de la hija que Fernando II tuvo con Joana Nicolau, y que fue esposa de Bernardino Fernández de Velasco, I duque de Frías, III conde de Haro y VII condestable de Castilla.

33 Arxiu Monestir de Montsió (AMM). Capbreu minor, fol. 100r-v.

34 AMM. Llibre d'Antiguedats, fol. 11r. 
LLIBRE DE CONFRARIA DEL ROSER DEL ANY 1489 DEL MONASTERIO DE SANTA MARÍA DE MONTESIÓN DE BARCELONA: UN EJEMPLO DE RED DEVOCIONAL CONCEPCIÓN RODRÍGUEZ-PARADA Y NÚRIA JORNET BENITO

de $\mathrm{N}^{\mathrm{a}} \mathrm{Sr}{ }^{\mathrm{a}}$ del Roser, en la iglésia del present convent de Montision, constuïda de diferents rèddits y partín de censos [...]. Per la molta devoció tenia a Ntra. Sra. del Roser, i per cumplir la voluntat de la Illma. Da Joana d'Aragó sa filla en distribuir i convertir perpetuament a sa voluntat, en la obra i conservació de la capella de Ntra. Sra. del Roser donà i consignà los censos i tributs següents» ${ }^{35}$.

La lectura atenta de estos fragmentos confirma la información contenida en un privilegio, que se conserva en el archivo conventual, fechado en Barcelona el 1 de septiembre de $1487^{36}$, que da fe de la existencia de una capilla dedicada a la Virgen del Psalterio o Rosario y de la solicitud que la priora dirige a Guillem Llull, canónigo y vicario general del obispo de Barcelona, para que los fieles que visiten la capilla en fechas señaladas del calendario litúrgico reciban indulgencias. El privilegio anuncia la preexistencia de la cofradía ${ }^{37}$, porque, según Caterina Capdevila ${ }^{38}$, las hermandades se fundan antes de que se construyan las respectivas capillas, como son anteriores también al encargo de la imagen o retablo de su santo patrón. En este sentido, para el historiador Josep M. ${ }^{a}$ Marquès es difícil precisar la fecha en que fueron fundadas la mayor parte de las cofradías. Los legados y beneficios que reciben son muestras inequívocas de una «actividad consolidada y una preexistencia relativamente larga ${ }^{39}$; sin embargo, pueden no ser relevantes para fijar el día fundacional. Añade Marquès que las cofradías fundadas en iglesias monásticas pudieran haber evolucionado a partir de una «fraternidad espiritual» entendida como una participación en los cultos que se realizaban en esos templos ${ }^{40}$. Este argumento corrobora la hipótesis de la mayor antigüedad de la cofradía rosariana de Montesión.

\section{El Llibre de Confraria del Roser DEL ANY 1489}

Tipológicamente el libro de cofradía es un documento de inscripción, registro o libro de matrícula de sus miembros. Gazzini sitúa esta tipología documental en el marco de un conjunto de documentación que incluye tanto aquellos documentos producto de la gestión interna de la cofradía (junto a reglamentos o estatutos, libros de cuentas u otros documentos de la administración patrimonial, inventarios de bienes, necrologios...), como aquellos de procedencia externa que pueden ser conservados en parte por la cofradía (privilegios pontificios y episcopales que aprueban la fundación, conceden indulgencias o consagran altares, por ejemplo, junto a documentación recibida de diversas autoridades

35 AMM, Capbreu minor, fol. 99r-v.

36 AMM, Indulgencias concedidas a la capilla de N. S. del Roser del convento de Montsió (1487), pliego 0 , número 1 .

37 Rodríguez-Parada, «Los orígenes de la Cofradía del Rosario», pp. 417-418.

38 Capdevila, Caterina. "Les confraries del Roser com a comitents de retaules en els segles XVI, XVII i xviII. El cas de la confraria del Roser d'Olot». En BASSEgoda, Bonaventura; GARRIGa, Joaquim y PARÍs, Jordi (eds.). L'época del Barroc i els Bonifas. Actes de les Jornades d'història de l'art a Catalunya; Valls, 1, 2 i 3 de juny de 2006. Barcelona: Universitat de Barcelona, 2007, p. 301.

39 Marquès Planagumà, Josep María. «Confraries medievals del bisbat de Girona». Annals de l'Institut d'Estudis Gironins, 1994, vol. 34, p. 346.

40 Ibidem, p. 341. 
LLIBRE DE CONFRARIA DEL ROSER DEL ANY 1489 DEL MONASTERIO DE SANTA MARÍA DE MONTESIÓN DE BARCELONA: UN EJEMPLO DE RED DEVOCIONAL

públicas, como la real y la municipal, actas notariales, etc. $)^{41}$. Siguiendo la argumentación de Trenchs y Cárcel ${ }^{42}$, el libro de miembros o de matrícula constituiría el segundo de los estadios documentales en la producción documental de una cofradía, junto al acta de fundación y las constituciones u ordenanzas. De hecho, el volumen que analizamos es el «segundo» libro de la cofradía del Roser. Desgraciadamente, no hemos localizado el primero en el que seguro estaría inscrita la fundadora y su círculo más íntimo ${ }^{43}$.

Se trata en todo caso de un tipo de fuente cuya importancia ya ha sido subrayada por la historiografía de las cofradías como «indispensabile per approfondire tematiche quali il raporto tra confraternite ed assetto politico-instituzionale locale, il numero di membri e il loro ceto sociale, la presenza femminille nella vita confraternale, gli orientamenti spirituali in raporto ad altre aggregazioni religiose, nonché per apportare contributi a studi di demografia» ${ }^{44}$. El carácter nominal de esta fuente y las anotaciones relativas a la filiación familiar, profesión y procedencia geográfica, han posibilitado, asimismo, la aplicación del método prosopográfico a la Edad Media. En este sentido, el historiador alemán Gerd Tellenbach en 1957 fue el primero en manifestar explícitamente la utilidad de esta metodología en los libri fraternitates o libros de registro de las cofradías (también aplicable a otras fuentes como los memoriales y libri vitae) para construir un corpus de todas las personas conocidas en una época o en un espacio ${ }^{45}$.

Nuestro manuscrito, en soporte pergamino y con cubierta del mismo material, consta de 116 folios $^{46}$. El contenido se organiza por días (de la semana, número y mes) a modo de epígrafe, y bajo cada uno de ellos se inscriben los nombres de los cofrades. De algunos, se indica además su profesión y lugar de procedencia. A otros se añade el grado de parentesco que guardan entre sí; y, a menudo, estos aparecen agrupados por unidades familiares: hijos e hijas, esposos, sobrinos, etc. ${ }^{47}$. En un

41 GazzINI, «Gli archivi delle confraternite», pp. 370-371.

42 Trenchs Òdena, Josep L. y Cárcel Ortí, M.a Milagros. «Notas en torno al estudio de las cofradías medievales y modernas. La Cofradía del Santisimo Cristo en la Iglesia del Salvador de Valencia (16161618)». Annals IDECO, 1984, vol. III, p. 83.

43 Sin duda, siguiendo la interesante reflexión de Gazzini, la conservación de este conjunto documental sería en su mayor parte producto de la conciencia archivística, de la voluntad de conservar la memoria de entidades como un monasterio u otra institución eclesiástica, un hospital, etc. Vid. nota 30.

44 Pezzola, Rita. "Et in arca posui». Scritture della confraternità della Beata Vergine Assunta di Morbegno, diòcesi di Como (sec. XV-XX). Morbegno: Adfontes, 2012, p. 25 <http://www.adfontes.it/biblioteca/ scaffale/arca/etinarca.pdf> [Consulta: 10/04/2019].

45 Karl Schmid y Joachim Wollasch, discípulos de Tellenbach, fundaron el proyecto «Societas et fraternitas" con la finalidad de recopilar la información contenida en los libri memoriales, libri vitae, los libros de registro de cofradías, etc. La labor de ambos contribuyó al desarrollo de este tipo de estudios como lo prueba la publicación desde 1980 de la revista Medieval Prosopography: History and Collective Biography por parte del Medieval Institute Publications at Western Michigan University.

46 Llibre de Confraria del Roser del any 1489. Archivo Histórico de la Provincia de Aragón de la Orden de Predicadores (AHPA).

47 «Barthomeu Plandiura pagès e Barthomeua sa muller (e fill Johan Plandiura), Margarita sa filla donzella, Johanna sa filla donzella, altra filla Catalina donzella, altra filla Sebastiana donzella» (fol. 2v). "Esclarmonda Coll, son fill Thomas Coll, sa muller Francina Coll, Johan Basoles, nebot seu» (fol. 8v). "Aldonsa muller de'n Pere Vidal flassader de Barchinona, la dona na Elionor de’n Reffel Ferigola barber, Jacme Guerau fill de la dita dona Aldonsa Vidala e Johana, neta de la dita dona» (fol. 3v). 
LLIBRE DE CONFRARIA DEL ROSER DEL ANY 1489 DEL MONASTERIO DE SANTA MARÍA DE MONTESIÓN DE BARCELONA: UN EJEMPLO DE RED DEVOCIONAL CONCEPCIÓN RODRÍGUEZ-PARADA Y NÚRIA JORNET BENITO

número importante de ocasiones consta que los cofrades inscritos están difuntos (defunct, defuncta $)^{48}$.

Aunque desconocemos el proceso de producción del documento y el de inscripción o matrícula de los cofrades, algunas evidencias documentales nos aportan algunos elementos. Así, por ejemplo, el documento puede hacer referencia explícita a quién ha inscrito y redactado una lista concreta. Tal es el caso de Roger Castell, presbítero de la villa de Moià, que en un día concreto, martes 23 de junio, escribe y anota los cofrades, empezando por él mismo ${ }^{49}$. También el de mossèn Jaume Calbó, que, tras inscribirse él mismo y a sus dos hermanos, aporta una nutrida relación de 1.178 nombres, de los que los 149 últimos son «difuntos» ${ }^{50}$ (Figura 1). Aunque lo desconocemos para el caso de la cofradía del Rosario de Montesión, sabemos que en la cofradía del Rosario del convento de religiosas predicadoras de Sanlúcar de Barrameda era un dominico, con licencia de la orden, el encargado de hacer las inscripciones ${ }^{51}$.

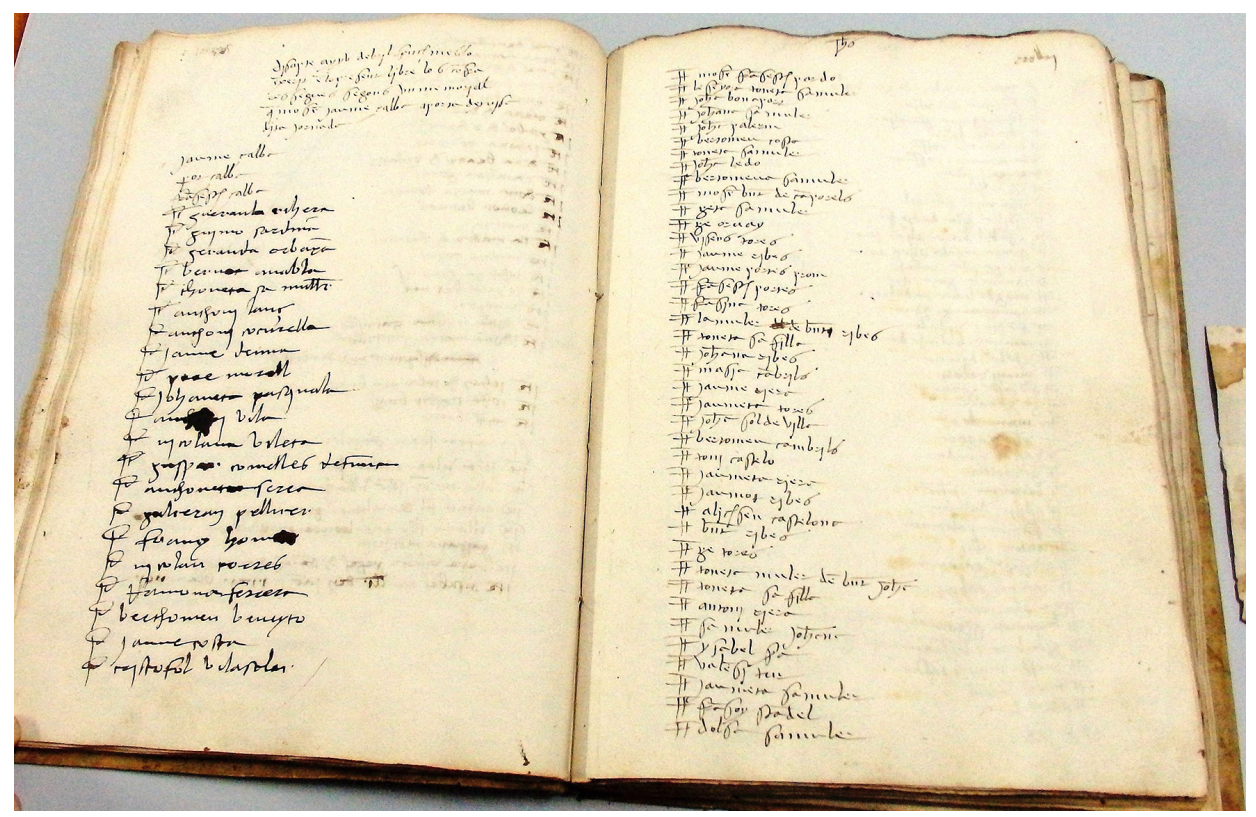

Figura 1.

48 Tan solo en una ocasión consta una información más allá del nombre, filiación, ocupación, geografía; y se trata justamente de una nota al margen con el símbolo de la cruz: «(+) Vuy fou sotarrada la cusina de'n Capell qui estava als Ollers Blanchs» (fol. 66v).

49 «Dit die e any scriu jo Roger Castell prevere de la vila de Moyà del bisbat, mi mateix e los que's segueix de la dita vila. Primo jo dit Roger Castell» (fol. 70v).

50 «Tots los demunt (...) són aportats scrits de pròpia mà mia per mi Jaume Calbó» (fol. 36v).

51 Marchena Hidalgo, Rosario. «El libro de la Regla de la Cofradía del Rosario de Sanlúcar de Barrameda». Laboratorio de Arte, 2003, vol. 16, p. 109 <http://hdl.handle.net/11441/56570> [Consulta: 10/04/2019]. Esta cofradía estaba radicada en el convento de dominicas de la Madre de Dios hasta que se construyó el de Santo Domingo de frailes predicadores. 
LLIBRE DE CONFRARIA DEL ROSER DEL ANY 1489 DEL MONASTERIO DE SANTA MARÍA DE MONTESIÓN 176 DE BARCELONA: UN EJEMPLO DE RED DEVOCIONAL CONCEPCIÓN RODRÍGUEZ-PARADA Y NÚRIA JORNET BENITO

Curiosamente, se ha conservado dentro del volumen un billete pequeño con unos nombres que aparecen después inscritos en el códice (Figura 2) ${ }^{52}$, dato que podría reflejar distintos momentos en la producción del documento, o la existencia de borradores que debían pasarse después al libro original. Cabe subrayar que el contenido del billete se encuentra tachado, siguiendo, pues, la escritura de redacción propia del documento notarial.

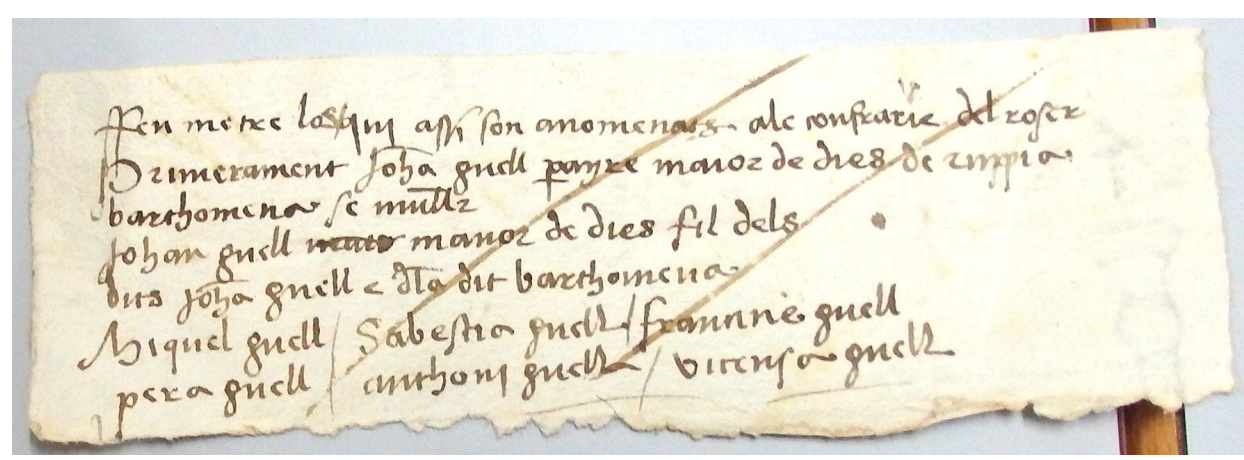

FiguRA 2.

Por el contrario, a veces, en una lista escrita por una misma mano, se aprecia un nombre con una caligrafía distinta que denotaría quizás una inscripción autógrafa (Figura 3) y, consecuentemente, una inscripción «en tiempo real» ejecutada por el propio cofrade.

Si bien no se especifica a qué obedece la inscripción bajo un día concreto, sí que sabemos de su importancia. Alano fijó que todos los cofrades debían anotar obligatoriamente su nombre en un registro, lo cual era visto como manifestación pública de los lazos de solidaridad entre ellos y un signo de su inscripción en el «libro de la vida » ${ }^{53}$. En todo caso, como veremos, la presencia de nombres procedentes de una amplia geografía peninsular permite intuir que no se exigía la presencia física de los cofrades para ser inscritos y admitidos en lo que Marquès denomina «confraria nominal». Una dinámica que él mismo constata también para el caso de las cofradías medievales de la diócesis de Girona ${ }^{54}$. O, como afirma Capdevila, el formar parte de una cofradía, al menos en sus inicios, no era tanto un acto participativo como una garantía de salvación de las almas. La inscripción situaba al cofrade en una cadena de gracias e indulgencias, suficiente para formar parte de una comunidad espiritual, quedando a su cargo el hecho de rezar el Rosario y seguir el resto de obligaciones fijadas en los estatutos ${ }^{55}$.

52 En el libro: «Feu metre los qui así són anomenats en la confraria del Roser. Primerament Johan Guell, peraire maior de dies, de Ruppià; Barthomeua, sa muller; Johan Guell, manor de diez, fill dels dits Johan Guell e de la dita Barthomeua; Miquel Guell; Sebastià Guell, Francine Guell; Pera Guell; Anthoni Guell; Vicensa Guell» (fol. 83).

53 Duval, André. «Rosaire». En Dictionnaire de spiritualité, ascétique et mystique: doctrine et histoire. Paris: Beauchesne, 1988, tomo 13, p. 949.

54 Marquès Planagumà, «Confraries medievals», p. 336.

55 Capdevila, La devoció del Roser a la diòcesi de Girona, p. 94. 
LLIBRE DE CONFRARIA DEL ROSER DEL ANY 1489 DEL MONASTERIO DE SANTA MARÍA DE MONTESIÓN DE BARCELONA: UN EJEMPLO DE RED DEVOCIONAL CONCEPCIÓN RODRÍGUEZ-PARADA Y NÚRIA JORNET BENITO

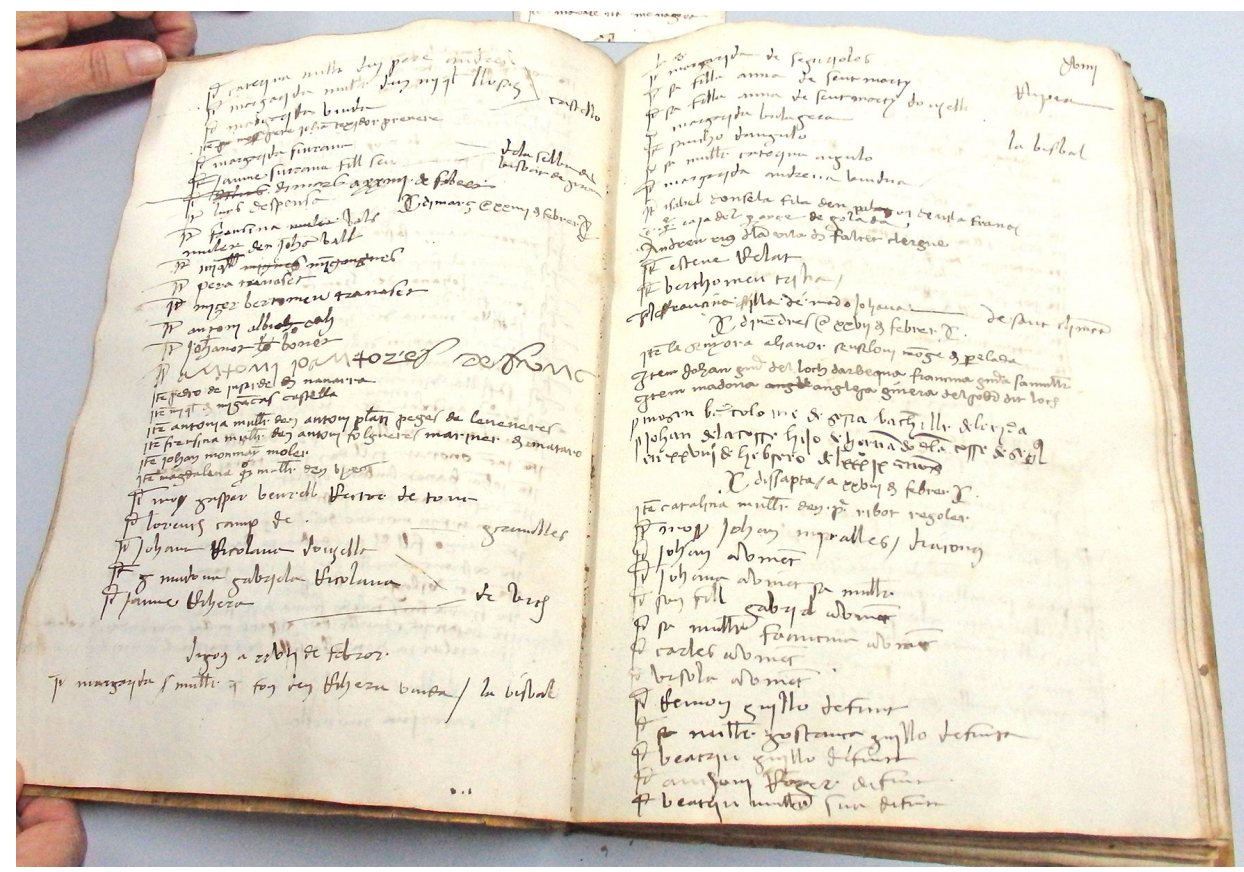

Figura 3.

¿Qué paisaje espiritual nos descubre esta fuente documental? ¿Qué radiografía social (en cuanto a género, oficio, estamento, edad) nos descubre y cuál es la topografía de la devoción al Rosario? ¿El análisis del códice permite observar una presencia significativa de mujeres, tal y como ha podido establecer la historiografía de las cofradías desde la perspectiva de la historia de las mujeres? Y, finalmente, ¿podemos trazar una red de conexión con la fundadora, doña Juana de Aragón, o con su círculo cortesano más próximo?

La primera constatación es que el libro de cofradía refleja de manera amplia la sociedad del momento en sus edades (jóvenes y mayores), categorías civiles (solteros, casados), categorías sociales (nobleza, estamentos urbanos, artesanado), profesiones y orígenes geográficos en un marcado carácter «interclasista», o, en palabras de Capdevila, las cofradías son asociaciones «verticals obertes»" ${ }^{56}$. Se confirma, pues, la apreciación de Gazzini en el sentido de que pueden ser consideradas como unos «gruppi comunitari ove prendevano corpo le aspirazioni spirituali e i bisogni sociali e di relazione degli individui, ${ }^{57}$. Efectivamente, en algunas definiciones de cofradía o fraternidad se deja entrever el concepto de "comunidad ideal», que subraya la cohesión social por encima de barreras de género, clase o geografía ${ }^{58}$.

56 Capdevila, La devoció del Roser a la diòcesi de Girona, p. 157.

57 GaZZINI, «Studi confraternali», p. X.

58 Froeschlé-Chopard, Marie-Hélène. «L'évolution des pénitents en Provence Orientale. XVIII ${ }^{\grave{ }}$ XIX ${ }^{\mathrm{è}}$ siècles». Revue d'Histoire Moderne et Contemporaine, 1993, vol. XXX, pp. 623-629. Citado por CAPDEVILA, La devoció del Roser a la diòcesi de Girona, p. 33. 
LLIBRE DE CONFRARIA DEL ROSER DEL ANY 1489 DEL MONASTERIO DE SANTA MARÍA DE MONTESIÓN 178 DE BARCELONA: UN EJEMPLO DE RED DEVOCIONAL

CONCEPCIÓN RODRÍGUEZ-PARADA Y NÚRIA JORNET BENITO

La cofradía, en otras palabras, ejercerá una función de integración simbólica o lo que en un contexto similar Garí ha denominado "aglutinantes simbólicos de la comunidad», en su capacidad de actuar como crisol de lazos simbólicos, de generar identidad y fomentar sociabilidades, en este caso, en torno al culto a una misma advocación, de carácter universal y general a la vez ${ }^{59}$.

La inclusión en muchas ocasiones de la unidad familiar permite integrar un número importante de personas jóvenes, hijos e hijas, doncellas, e incluso menores de edad ${ }^{60}$. Dinámica que permite integrar en alguna ocasión al personal doméstico ${ }^{61}$. Esta referencia al conjunto de una unidad familiar extensa, que habita una casa o un «mas» se consolidará como práctica de inscripción en las cofradías modernas, como se constata en el caso de la diócesis de Girona ${ }^{62}$.

El perfil profesional de los cofrades nos muestra la variedad de oficios presentes en un marco urbano bajomedieval: payeses, labradores, colchoneros, algodoneros, menestrales, plateros, mercaderes, molineros, militares, zapateros, barberos, tejedores, panaderos, velluters, carpinteros, mercaderes, sastres, notarios, doctores en leyes, carpinteros, estudiantes, manteros, herreros, cesteros, chapineros, cuchilleros, boteros, calafates, criadas, carniceros, coraleros, revendedoras, maestros de casas... A veces, de la misma manera que hay una agrupación de cofrades por procedencia geográfica, parece haberla también por oficios, como se percibe a la hora de inscribir, por ejemplo, a gentes de la mar (calafates y marineros), de la metalurgia (herreros y braseros), estudiantes juntos, barberos juntos, beneficiados juntos.

La significación de la devoción y el culto al Rosario da, asimismo, a la cofradía un carácter supralocal que va más allá de los límites de una ciudad e incluso de un reino. El libro se abre, así, a realidades geográficas más allá de la ciudad de Barcelona, ya que el radio de influencia de la hermandad alcanzaba la totalidad del principado de Cataluña (Blanes, Tortosa, Ripoll, Besalú, Vinyoles, El Papiol, Lleida, Balaguer, La Fatarella, Berga, Pineda, Sabadell, Agramunt, Seu d'Urgell, Tortosa, Tossa, Igualada, Reus, Olot, Girona, Àger, Salàs, Manresa, Santa Llogaia, Sant Joan Despí, etc.); se extendía al resto de territorios de la Corona de Aragón (Mallorca, Zaragoza, Perpinán, Valencia, Menorca, Barbastro, Cerdeña, Sicilia, Cáller, Gandía) y también a Castilla (Medinaceli, Guadalajara, Murcia, Sevilla), Francia e incluso Flandes y Bretaña. Estos nombres procedentes de otras geografías españolas pueden aparecer dentro de una lista, con sus respectivos orígenes $^{63}$, o bien una relación de personas inscritas bajo un epígrafe o título concreto, como por ejemplo «Castilla».

59 Garí, Blanca. «La política de lo sagrado en la Barcelona medieval. De la “inventio Santae Eulaliae” a las leyendas mercedarias». Imago Temporis. Medium Aevum, 2010, vol. IV, p. 490.

60 «Primer mossèn Francesch Fàbrega, cap de guayta del senyor Rey. Item sa muller Rafaela Fàbrega. Item son fill Johan Francesch Fàbrega. Item sa fill Francina donzella. Item altra filla Caterina donzella» (fol. 2r). «Fernando Palaso, menor de dies; Bernat Boniver, manor» (fol. 61r). «Franciscana, menor de diez» (fol. 66r).

61 «Cristófol Morell, sa muller, Caterina Morell, sa criada Caterina» (fol. 5r).

62 Capdevila, La devoció del Roser a la diocesi de Girona, pp. 159-160.

63 «Mossèn Alonso de Barros, portugués, Lois Ximénez de Jaca, Pero Mexia de Tudela, Pere Jordà, francés; la familia Panques, de Perpińán, Pere Vilar, peraire de Girona, madona Iolant, muller de Gabriel Lobera, de Càller, Luís Montagut de València, Joana flamenca», son algunos nombres inscritos en el mes de enero. 
LLIBRE DE CONFRARIA DEL ROSER DEL ANY 1489 DEL MONASTERIO DE SANTA MARÍA DE MONTESIÓN DE BARCELONA: UN EJEMPLO DE RED DEVOCIONAL CONCEPCIÓN RODRÍGUEZ-PARADA Y NÚRIA JORNET BENITO

Destaca la presencia de nombres de cofrades procedentes de un amplio territorio rural en el caso catalán ${ }^{64}$, iniciando de hecho una expansión que la historiografía moderna ha significado como la red más extensa de una cofradía devocional, que se introducirá con fuerza en prácticamente todas las parroquias a lo largo del último cuarto del siglo XvI y la primera mitad del xviI, mediante la prédica de la orden dominica y con la ayuda de los párrocos y las élites locales ${ }^{65}$.

El Llibre, además de evidenciar la multiplicidad de oficios nos permite, asimismo, ubicar socialmente a los miembros de la cofradía y su mayor éxito o difusión en unos u otros estamentos. De nuevo, encontramos cofrades pertenecientes a todas las clases sociales: nobles ${ }^{66}$, representantes del patriciado urbano ${ }^{67} \mathrm{y}$, aunque en menor proporción, miembros del estamento eclesiástico como presbíteros y también algunos frailes y monjas ${ }^{68}$. Está presente también personal doméstico no necesariamente incluido en la unidad familiar ${ }^{69}$.

En todo caso sí que se observa una mayor implicación del estamento noble en las inscripciones procedentes de Aragón y del reino de Castilla. En cambio, la mayoría de los otros cofrades, tanto religiosos (mercedarios, jerónimos o cistercienses, por ejemplo) como miembros del pueblo llano, burgueses o artesanos, en su mayoría eran originarios o vivían en Cataluña.

La participación de las mujeres en las cofradías bajomedievales es ya un dato constatado y confirmado por la historiografía, como lo es el protagonismo femenino en las diversas manifestaciones de la religiosidad medieval «laical» (que incluye no solo las cofradías o fraternidades espirituales, sino también la expansión del tercer orden y de las comunidades de beguinas o mulieres religiosae entre las filas femeninas $)^{70}$.

Giovanna Casagrande, en un estudio pionero, afirmó que la «female participation in Italian and European confraternities was not insignificant ${ }^{71}$; aunque ya precisó que esta admisión «sin barreras», respecto a los géneros, podí limitarse después en la gestión material de la fraternidad con la supremacía masculina en sus estructuras jerárquicas y de poder ${ }^{72}$.

64 Cofrades procedentes de localidades como Sant Jaume dels Domenys, Peratallada, Ulldecona, Rubió, entre muchísimas otras, y que representan una amplia parte de la geografía catalana.

65 Puigvert i Solà, Joaquim M. «Los párrocos y las redes de sociabilidad parroquial en el mundo rural de la Cataluña moderna: historiografia e historia». Obradoiro de Historia Moderna, 2013, vol. 22, p. 200.

${ }_{66}$ Por ejemplo: «La Merquesa de Villena» (fol. 33r).

67 Por ejemplo: «La senyora Johanna muller de Gilbert, ciutadà al carrer dels Flaçadés» (fol. 7r).

68 Por ejemplo: «Mossèn Miquel Vinader, prevere en la Seu de Tortosa» (fol. 4v); "Aldonça Pallares, monja del monestir de Vallbona» (fol. 54r); «Mestre Francesch Colell frara de sant Francesch» (fol. 6r); "mossèn Joan Camps, beneficiat de la Seu» (fol. 6v); «Bartomeu Salançó, canonge de Besalú» (fol. 8r).

69 "Johan Biscahino, escuder de la senyora comtesa de Quirra» (fol. 5 r). O en un perfil más cortesano: «Dolius tamborino [probablemente músico] de la senyora Johana d'Aragó» (fol. 55v).

70 Muñoz Fernández, Ángela. «Las mujeres en los ámbitos institucionales de la religiosiddad laica: las cofradías devocionales castellanas (ss. XII-Xv)». En Muñoz Fernández, Ángela y Graña Cid, M. ${ }^{a}$ del Mar (eds.). Religiosidad femenina: expectativas y realidades (siglos VIII-XVIII). Madrid: Asociación Cultural Al-Mudayna, 1991, pp. 93-114.

71 Casagrande, Giovanna. "Women in Confraternities between the Middle Ages and the Modern Age. Research in Umbria». Confraternitas, 1994, vol. 5, n. ${ }^{\circ}$ 2, p. 4.

72 Pastore, Stefania; Prosperi, Adriano y Tersptra, Nicholas (coords.). A Brotherhood and Boundaries. Fraternità e barriere. Pisa: Edizione della Normale, 2011, p. XII. 
LLIBRE DE CONFRARIA DEL ROSER DEL ANY 1489 DEL MONASTERIO DE SANTA MARÍA DE MONTESIÓN DE BARCELONA: UN EJEMPLO DE RED DEVOCIONAL CONCEPCIÓN RODRÍGUEZ-PARADA Y NÚRIA JORNET BENITO

En algunas cofradías la presencia femenina era relevante, si no superior a la masculina, como han mostrado investigaciones recientes que han analizado justamente los libros de miembros (matricole), en especial para el área italiana. Gazzini ${ }^{73}$, por ejemplo, al estudiar el códice con la regla, la bula fundacional y la matrícula de los inscritos en la cofradía del «Consorzio dello Spirito Santo» de Piacenza (1250-1290), constata que, del total de 800 miembros, el $81 \%$ son mujeres. Brolis ${ }^{74}$, por su parte, también en Italia, ha encontrado más de 1.700 mujeres afiliadas a la confraternidad de la Misericordie Maggiore de Bérgamo, según se desprende de su Liber fraternitatis. Es más, entre 1265 y 1276 se adhieren 1.004 mujeres, lo que representa un 58\% de los cofrades. Como ha señalado recientemente Anna Esposito, si bien no es frecuente encontrar una lista de nombres de hermanas tan numerosa como las que señalan Brolis y Gazzini, la presencia femenina en las cofradías es un dato inapelable. Esposito introduce, sin embargo, una interesante gradación en este protagonismo: un primer nivel de adhesión a una fraternidad espiritual, compartiendo sus beneficios espirituales con el padre o el marido; un segundo nivel de inscripción que podría implicar para la hermana cofrade precisas obligaciones devocionales o de otra índole, en igualdad con el hombre; un tercer nivel, en el que la presencia femenina es más intensa y visible y puede expresarse en formas más autónomas ${ }^{75}$.

Sin duda, como afirma Casagrande, la expansión de la devoción mariana en la espiritualidad medieval enfatizó la presencia de mujeres en cofradías especialmente dedicadas al Rosario ${ }^{76}$. Si bien muchas de las cofradías rosarinas son mixtas, como la de Barcelona, es cierto también que las cofradías exclusivamente femeninas adoptan de manera mayoritaria advocaciones marianas ${ }^{77}$.

Del análisis de las características y el número de las mujeres cofrades del Llibre segon, se difiere un perfil muy diverso tanto en lo que se refiere a su estado civil, estatus social, edad o incluso condición religiosa. Así, podían ser solteras (donzelles), casadas (muller), viudas; encontramos a laicas, monjas terceras, beatas, emparedadas; a miembros de la nobleza, personal doméstico; y también niñas, jóvenes, adultas y ancianas ${ }^{78}$. Se perfila incluso en algunos momentos inscripciones de mujeres en un conjunto más o menos homogéneo, como las seis mujeres de Tossa (Girona) anotadas juntas, aunque sin ninguna

73 Gazzini, Marina. «Donne e uomini in confraternita: la matricola del Consorzio dello Spirito Santo di Piacenza (seconda metà XIII secolo)». Archivio Storico per le Province Parmensi, 2000, vol. LII, pp. $253-274$. Panorama italiano sintetizado en: Esposito (2009).

74 Brolis, Maria Teresa. «Il valore di una presenza. Le donne nella confraternite medievali di Bergamo». En Casagrande, Giovanna (a cura di). Donne tra Medioevo ed Età Moderna in Italia. Ricerche. Perugia: Morlachi, 2004, pp. 73-89.

75 Esposito, Anna. «Donne e confraternite». En Gazzini, Studi confraternali, p. 77, vid. nota 3 <http://www.rmoa.unina.it/2320/1/4.Esposito.pdf> [Consulta: 10/04/2019].

76 Casagrande, "Women in Confraternities», p. 5. Esposito, «Donne e confraternite», p. 54.

77 Casagrande, «Women in Confraternities», p. 11, documenta cofradías del Rosario mixtas como las de Terni, Perugia, Casalina y Sant'Enea (Perugia), Cannaiola (Spoleto); o exclusivamente femeninas, como las de Castelrivoso (Spoleto), Passignano y Badiola (Perugia).

78 Algunos ejemplos más: «Elionor Cruelles, enfermera, monja del monestir de Sant Daniel de Girona» (fol. 68v); "Margarida muller de Miquel Terrats viuda» (fol. 3v); «Margarita, negra de la senyora dona Aldonça contesa de Prades» (fol. 4v). 
LLIBRE DE CONFRARIA DEL ROSER DEL ANY 1489 DEL MONASTERIO DE SANTA MARÍA DE MONTESIÓN DE BARCELONA: UN EJEMPLO DE RED DEVOCIONAL CONCEPCIÓN RODRÍGUEZ-PARADA Y NÚRIA JORNET BENITO

referencia de ocupación o espacio ${ }^{79}$. Si bien no se ha realizado un exhaustivo cómputo del número de hermanas cofrades, una muestra nos permite realizar una interesante aproximación a las proporciones entre sexos. Así, a partir de la lista ya comentada que aporta mossèn Calbot, constatamos que, del conjunto de 1.029 cofrades vivos, 482 son mujeres, lo que supondría algo más del $46 \%$.

Es evidente que la cofradía de Montesión gozaba del favor de la nobleza castellano-aragonesa, seguramente por ser de fundación real, ya que sus linajes apuntan a las familias más distinguidas y poderosas del reino y, por tanto, a la fundadora doña Jua$n a^{80}$ y a su padre, Fernando $\mathrm{II}^{81}$, e incluso a la reina Isabel ${ }^{82}$. La aplicación del método prosopográfico -aún incipiente- posibilita mostrar que, al menos en Castilla y Aragón, la corona ejercía de aglutinante de redes y relaciones devotas y cortesanas tejidas en torno a ella. A la vez, muestra también cómo dońa Juana, a pesar de ser fruto de un amor de adolescencia del rey Católico, estaba plenamente integrada en la familia real.

\section{Conclusiones}

La propia existencia de la cofradía del convento de Montesión al configurar un espacio de religiosidad protagonizada por un tejido laico amplio y diverso, reflejo a su vez del papel e implicación del laicado en las manifestaciones espirituales medievales, justifica la inserción de este trabajo en el proyecto de investigación en el que se enmarca. La cofradía es un espacio simbólico en torno a una devoción mariana, la del Rosario, que arranca con fuerza por entonces para consolidarse en la época moderna a la vez que pone de relieve la existencia de una red de conexiones entre fieles, y entre estos y las monjas o frailes. Refleja también, ciertamente, la integración del convento en su entorno urbano y social más o menos cercano, ya que una de sus capillas, a la que el pueblo llamaba (vulgo dicte) «Beate Marie Psalteri sive Rosarii», tal como reconoce el privilegio episcopal de 1487, llegó a formar parte de la topografía devocional de la ciudad de Barcelona.

Como creemos haber demostrado, las cofradías fueron uno de los ejes vertebradores de la sociedad, en cuanto que englobaban dentro de ellas a los núcleos familiares, constituyendo sin duda una ampliación de las propias familias naturales, una gran familia espiritual formada por todos los hermanos y hermanas, que encontraron en ellas un cauce apropiado para su desarrollo personal y cristiano. La inscripción de los cofrades en los libri fraternitates es una manifestación pública de los lazos de identidad y solidaridad que los unen, a la vez que es una muestra de su inscripción en el «libro de la vida».

79 «Madalena Puig, Baronata Frou, Angelina Pujola, Felipa Portella, Alionor Rihera, Caterina Dertera» (fol. 8).

80 Rodríguez-PARAda, Concepción. «El doble patronazgo espiritual y cultural ejercido por Juana de Aragón (1469-1511)» [en prensa]. (fol. 86v).

81 «Senyora Elionor, muller de [...] Luys Gonsales, secretari de la magestat de nostro señor lo rey»

82 Entre otros: «La egregia senyora donya Maria comtesa de Coronya, dona Beatriz de Curenya, la senyora dona Anna de Mandossa, la senyora dona Beatriz de Mandossa, donya Iolant d'Aragón» (fol. 54v). También: «Pedro y don Álvaro de Luna, Pedro de Mendoza, Teresa Enríquez», etc. (fol. 72r). 
LLIBRE DE CONFRARIA DEL ROSER DEL ANY 1489 DEL MONASTERIO DE SANTA MARÍA DE MONTESIÓN DE BARCELONA: UN EJEMPLO DE RED DEVOCIONAL

El análisis de los nombres inscritos, junto a los datos de extracción social, procedencia, sexos, ocupación, que detalla el libro de Montesión, confiere al espacio de la cofradía un marcado carácter interestamental. Amplio es también su radio de influencia, con la presencia de nombres procedentes de diversas localidades representativas de toda la geografía catalana, alcanzando territorios del reino de Aragón en el Mediterráneo, toda la Península Ibérica y, aunque en menor proporción, otros países europeos.

La presencia de nombres vinculados al círculo cortesano de la fundadora o en general a la monarquía -que se constata de manera particular en la zona castellana y aragonesa- permite introducir una red de relaciones tejidas en torno al poder y la corte, que aporta una conexión relacional más allá de la devoción y el culto al Rosario. Como también, en la zona catalana, una red que puede unir solidaridades en torno a una ocupación o ámbito laboral (gente de la mar, textil...).

En todo caso, nuestro análisis permite mostrar ya algunas de las características del panorama de las cofradías de la época moderna y, en especial, tras el Concilio de Trento: la popularidad de las cofradías que fomentan devociones de carácter general y universal (marianas, como las del Rosario, los Dolores o del Carmen; y eucarísticas, como las del Santísimo o de la Minerva); su expansión y diseminación en el mundo rural o en todo el territorio de un reino creando una densa red; y su voluntad de integrar toda una representación del cuerpo social, fomentando sociabilidades alrededor de una devoción ${ }^{83}$.

Se confirma la presencia de mujeres en lo que sería una hermandad mixta. Sus nombres aparecen de manera destacada junto al núcleo familiar, con su marido e hijos, si es el caso; o bien hijas doncellas, aunque también aparecen mujeres solas.

Las características de la fuente documental y la riqueza de datos que contiene el llibre segon permitirán en un futuro próximo llevar a cabo nuevas investigaciones para profundizar en estudios de carácter demográfico-social tales como la estructura de una unidad familiar (miembros y componentes), y también han de permitir la elaboración de un catálogo de oficios medievales, además de seguir avanzando en un análisis más específicamente prosopográfico, que extraiga nombres y relaciones de poder, y círculos de influencia en torno a una figura conocida, ya sea la de la fundadora, la de su padre, el rey Fernando, o la de la reina Isabel. Finalmente, el estudio de otros documentos, tanto del archivo conventual (Santa María de Montesión) como de otros centros de custodia (archivos provinciales de las órdenes mendicantes), puede acabar de completar la imagen de la cofradía, tanto en su funcionamiento (cuota, responsabilidades...), como en las prácticas devocionales que se desarrollaban (procesiones, misas, honras fúnebres...).

\section{REFERENCIAS BIBLIOGRÁFICAS}

Adriazola Acha, Susana. «Fragmentos de una vida: Ángela Pujades, escritura y devoción al Rosario». En Garí, Blanca (ed.). Vida de mujeres del Renacimiento. Barcelona: Publicacions i Edicions de la Universitat de Barcelona, 2007, pp. 163-185.

Adriazola Acha, Susana. Fragmentos de una vida: Angela Pujades (ca. 1491-1548). Escritura y devoción al rosario. Trabajo para optar al Diploma de Estudios Avanzados [inédito].

83 Puigvert i Solà, «Los párrocos y las redes de sociabilidad», pp. 199-202. 
LLIBRE DE CONFRARIA DEL ROSER DEL ANY 1489 DEL MONASTERIO DE SANTA MARÍA DE MONTESIÓN DE BARCELONA: UN EJEMPLO DE RED DEVOCIONAL CONCEPCIÓN RODRÍGUEZ-PARADA Y NÚRIA JORNET BENITO

Arias de SaAvedra, Inmaculada y López-Guadalupe Muñoz, Miguel Luis. «Las cofradías españolas de la Edad Moderna desde una óptica social. Tres décadas de avance historiográfico». Cuadernos de Estudios del Siglo XVIII, 2017, vol. 27, pp. 11-50<https://doi.org/10.17811/ cesxviii.27.2017.11-50> [Consulta: 20/12/2017].

Benítez Bolorinos, Manuel. «Las cofradías en el Reino de Valencia: análisis y claves interpretativas». Anuario de Estudios Medievales, 2006, vol. 36, n.o 2, pp. 553-581.

Brolis, Maria Teresa. «Il valore di una presenza. Le donne nella confraternite medievali di Bergamo». En Casagrande, Giovanna (a cura di). Donne tra Medioevo ed Età Moderna in Italia. Ricerche. Perugia: Morlachi, 2004, pp. 73-89.

Capdevila, Caterina. "Les confraries del Roser com a comitents de retaules en els segles XVI, XVII i XviII. El cas de la confraria del Roser d'Olot». En BASSEgOda, Bonaventura; GarRIgA, Joaquim y PARÍs, Jordi (eds.). L’època del Barroc i els Bonifas. Actes de les Jornades d'història de l'art a Catalunya; Valls, 1, 2 i 3 de juny de 2006. Barcelona: Universitat de Barcelona, 2007, p. 301.

Capdevila, Caterina. La devoció del Roser a la diòcesi de Girona del segle XVI al XIX: confraries $i$ imatges. Tesis doctoral dirigida por el Dr. Bonaventura Bassegoda. Universitat Autònoma de Barcelona, 2015 <http://hdl.handle.net/10803/322794> [Consulta: 10/04/2019].

Casagrande, Giovanna. "Women in Confraternities between the Middle Ages and the Modern Age. Research in Umbria». Confraternitas, 1994, vol. 5, n. ${ }^{\circ} 2$, 1994, pp. 3-13.

Colesanti, Gemma-Teresa; Garí, Blanca y Jornet Benito, Núria (coords.). Clarisas y dominicas. Modelos de implantación, filiación, promoción y devoción en la Peninsula Ibérica, Cerdeña, Nápoles y Sicilia. Firenze: Reti Medievali Firenze University Press, 2017.

Coll, José M.a. "Apóstoles de la devoción rosariana antes de Lepanto en Cataluña». Analecta Sacra Tarraconensia, 1955, 28, pp. 245-254.

Duval, André. «Rosaire». En Dictionnaire de spiritualité, ascétique et mystique: doctrine et histoire. Paris: Beauchesne, 1988, tomo 13, p. 949.

Egido López, Teófanes. «La religiosidad colectiva de los vallisoletanos». En Valladolid en el siglo XVIII. Valladolid: Ateneo, 1984, pp. 157-260.

Esposito, Anna. «Donne e confraternite». En Gazzini, Marina (a cura di). Studi confraternali. Orientamenti, problemi, testimonianze. Firenze: Reti Medievali, 2009, pp. 53-78, <http:// www.rmoa.unina.it/2320/1/4.Esposito.pdf> [Consulta: 10/04/2019].

Froeschlé-Chopard, Marie-Hélène. "L'évolution des pénitents en Provence Orientale. Xviri XIX ̀̇ siècles». Revue d'Histoire Moderne et Contemporaine, 1993, vol. XXX, pp. 623-629.

Garí, Blanca. «La política de lo sagrado en la Barcelona medieval. De la "inventio Santae Eulaliae" a las leyendas mercedarias». Imago Temporis. Medium Aevum, 2010, vol. IV, pp. 475-490.

Garí, Blanca. «Santa Maria de Montsió». Claustra. Catálogo de los Reinos peninsulares <http:// www.ub.edu/claustra/Monestirs/view/20> [Consulta: 26/01/2018].

Gazzini, Marina. «Donne e uomini in confraternita: la matricola del Consorzio dello Spirito Santo di Piacenza (seconda metà XIII secolo)». Archivio Storico per le Province Parmensi, 2000, vol. LII, pp. 253-274.

Gazzini, Marina (a cura di). Studi confraternali. Orientamenti, problemi, testimonianze. Firenze: Reti Medievali, 2009.

GazzinI, Marina. «Gli archivi delle confraternite: documentazione, prassi conservative, memoria comunitaria». En GazzinI, Marina (a cura di). Studi confraternali. Orientamenti, problemi, testimonianze. Firenze: Reti Medievali, 2009, pp. 369-377 <http://www.rmoa.unina. it/2331/1/15.Gazzini.pdf> [Consulta: 07/04/2019].

Godaracena Arboleda, Juan Carlos. «Creencias y devociones en las cofradías sevillanas de finales de la Edad Media y comienzos de la modernidad». Revista de Humanidades, 2016, 
LLIBRE DE CONFRARIA DEL ROSER DEL ANY 1489 DEL MONASTERIO DE SANTA MARÍA DE MONTESIÓN DE BARCELONA: UN EJEMPLO DE RED DEVOCIONAL

vol. 29, pp. 9-36 <http://revistas.uned.es/index.php/rdh/article/view/17215/14701> [Consulta: 07/04/2019].

Hernández Cabrera, Marisol. «La celda del convento una habitación propia. La vivencia de la clausura en la comunidad de dominicas de Montesión». Duoda. Revista d'Estudis Feministes, 2002, vol. 22, pp. 19-40 <http://www.raco.cat/index.php/duoda/article/viewFile/62697/90792> [Consulta: 22/12/2017].

Iradiel Murugarren, Paulino. "Corporaciones de oficio, acción política y sociedad civil en Valencia». En Cofradias, gremios y solidaridades en la Europa medieval. XIX Semana de Estudios Medievales. Estella, 20 a 24 de julio de 1992. Pamplona: Gobierno de Navarra, 1993, pp. 253-284.

Marchena Hidalgo, Rosario. «El libro de la Regla de la Cofradía del Rosario de Sanlúcar de Barrameda». Laboratorio de Arte, 2003, vol. 16, pp. 107-134 <http://hdl.handle. net/11441/56570> [Consulta: 10/04/2019].

Marquès Planagumà, Josep María. «Confraries medievals del bisbat de Girona». Annals de l'Institut d'Estudis Gironins, 1994, vol. 34, pp. 335-376.

Martín-Viveros Tajuelo, Antonio. «Las cofradías castellanas en la Edad Media: pasado, presente y futuro de la producción historiográfica». Espacio, Tiempo y Forma. Serie III. Historia Medieval, 2012, vol. 25, pp. 285-308.

Muñoz Fernández, Ángela. «Las mujeres en los ámbitos institucionales de la religiosiddad laica: las cofradías devocionales castellanas (ss. XII-Xv)». En Muñoz Fernández, Ângela y Graña CID, M. ${ }^{a}$ del Mar (eds.). Religiosidad femenina: expectativas y realidades (siglos VIII-XVIII). Madrid: Asociación Cultural Al-Mudayna, 1991, pp. 93-114.

Navarro Espinach, Germán. «Las cofradías medievales en España». Historia 396, vol. 4, n. ${ }^{\circ}$, 2014, pp. 107-133 <https://dialnet.unirioja.es/servlet/articulo?codigo=5627994> [Consulta: 07/04/2019].

Pastore, Stefania; Prosperi, Adriano y Tersptra, Nicholas (coords.). A Brotherhood and Boundaries. Fraternità e barriere. Pisa: Edizione della Normale, 2011.

Paulí Menéndez, Antonio. El Real Monasterio de Santa María de Monte-Sión de Barcelona. Barcelona: Bartrés, 1952.

Pérez González, Silvia María. «Mujeres y cofradías en la Andalucía de la Baja Edad Media». Historia. Instituciones. Documentos, 2012, vol. 39, pp. 185-211.

Pérez González, Silvia María. «Nuevas aportaciones al estudio de las cofradías y hermandades en la Castilla bajomedieval: el ejemplo de Jerez de la Frontera». Hispania Sacra, 2016, vol. 68, n. ${ }^{\circ} 138$, pp. 503-520 <https://doi.org/10.3989/hs.2016.032> [Consulta: 07/04/2019].

Pezzola, Rita. "Et in arca posui». Scritture della confraternità della Beata Vergine Assunta di Morbegno, diòcesi di Como (sec. XV-XX). Morbegno: Adfontes, $2012<$ http://www.adfontes.it/biblioteca/scaffale/arca/etinarca.pdf> [Consulta: 10/04/2019].

Puigvert i Solà, Joaquim M. Església, territori i sociabilitat, ss. XVII-XIX. Vic: Eumo, 2001.

Puigvert i Solà, Joaquim M. «Los párrocos y las redes de sociabilidad parroquial en el mundo rural de la Cataluña moderna: historiografia e historia». Obradoiro de Historia Moderna, 2013, vol. 22, pp. 167-206.

Rodríguez-Parada, Concepción. «Los orígenes de la Cofradía del Rosario del monasterio de Santa María de Montesión». En Colesanti, Gemma-Teresa; Garí, Blanca y Jornet BeniTO, Núria (coords.). Clarisas y dominicas. Modelos de implantación, filiación, promoción y devoción en la Peninsula Ibérica, Cerdeña, Nápoles y Sicilia. Firenze: Reti Medievali Firenze University Press, 2017, pp. 409-428.

Rodríguez-PARADA, Concepción. «El doble patronazgo espiritual y cultural ejercido por Juana de Aragón (1469-1511)» [en prensa]. 
LLIBRE DE CONFRARIA DEL ROSER DEL ANY 1489 DEL MONASTERIO DE SANTA MARÍA DE MONTESIÓN DE BARCELONA: UN EJEMPLO DE RED DEVOCIONAL CONCEPCIÓN RODRÍGUEZ-PARADA Y NÚRIA JORNET BENITO

Romero Mensaque, Carlos. «Los comienzos del fenómeno rosariano en la Espańa moderna. La etapa fundacional, siglos Xv y XvI». Hispania Sacra, 2014, vol. 66, n.o 2, pp. 243-278 <http://hispaniasacra.revistas.csic.es/index.php/hispaniasacra/article/viewArticle/419> [Consulta: 22/05/2017].

Serra Boldú, Valeri. Llibre d'or del Rosari a Catalunya. Barcelona: Imp. Oliva de Vilanova, 1925.

TATJER, Mercè. Burgueses, inquilinos y rentistas: mercado inmobiliario, propiedad y morfología en el centro histórico de Barcelona: La Barceloneta 1753-1982. Madrid: Consejo Superior de Investigaciones Científicas, 1998.

Tello Hernández, Esther. Aportación al estudio de las cofradías medievales y sus devociones en el reino de Aragón. Zaragoza: Fundación Fernando el Católico, 2013, pp. 19-20<https://ifc. dpz.es/recursos/publicaciones/33/20/_ebook.pdf> [Consulta: 20/12/2017].

Trenchs Òdena, Josep L. y Cárcel Ortí, M. ${ }^{a}$ Milagros. «Notas en torno al estudio de las cofradías medievales y modernas. La Cofradía del Santisimo Cristo en la Iglesia del Salvador de Valencia (1616-1618)». Annals IDECO, 1984, vol. III, p. 83.

Winston-Allen, Anne. Stories of the rose: the making of the rosary in the Middle Age. University Park: The Pennsylvania University Press, 1997. 
